\title{
Upper airway response in workers exposed to fuel oil ash: nasal lavage analysis
}

\author{
Russ Hauser, Salma Elreedy, Jane A Hoppin, David C Christiani
}

\begin{abstract}
Objectives-Among other constituents, fuel oil ash contains vanadium pentoxide, a known respiratory irritant. Exposure to ambient vanadium pentoxide dust has been shown to produce irritation of the eyes, nose, and throat. The usefulness of nasal lavage in detecting an inflammatory response to exposure to fuel oil ash among 37 boilermakers and utility workers was investigated.
\end{abstract}

Methods-A baseline lavage was performed on the morning of the first day back to work after an average of 114 days away from work (range 36 hours to 1737 days). A lavage was performed after exposure on the morning three days after the baseline lavage. Exposure to respirable particulate matter of diameter $\leqslant 10 \mu \mathrm{m}\left(\mathbf{P M}_{10}\right)$ and respirable vanadium dust were estimated with daily work diaries and a personal sampling device for respirable particulates. These estimates were made for each subject on each workday during the three days between lavages. For each subject, the adjusted change in polymorphonuclear cells was calculated by dividing the change in polymorphonuclear cell counts by the average of the counts before and after exposure. The association between the adjusted polymorphonuclear cell counts and exposure was assessed with multiple linear regression, adjusted for age and current smoking.

Results-Personal sampling (one to 10 hour time weighted average) showed a range of $P M_{10}$ concentrations of 50 to 4510 $\mu \mathrm{g} / \mathrm{m},{ }^{3}$ and respirable vanadium dust concentration of 0.10 to $139 \mu \mathrm{g} / \mathrm{m}^{3}$. In smokers the adjusted polymorphonuclear cell count was not significantly different from zero $(-0.1 \%, P>0.5)$, but in nonsmokers it was significantly greater than zero $(+50 \%, P<0.05)$. In both non-smokers and smokers, there was considerable variability in adjusted polymorphonuclear cell counts and a dose-response relation between these adjusted cell counts and either $\mathbf{P M}_{10}$ or respirable vanadium dust exposure could not be found.

Conclusion-A significant increase in polymorphonuclear cells in non-smokers but not smokers was found. This suggests that in non-smokers, exposure to fuel oil ash is associated with upper airway inflammation manifested as increased polymorphonuclear cell counts. The lack of an increase in polymorphonuclear cells in smokers may reflect either a diminished inflammatory response or may indicate that smoking masks the effect of exposure to fuel oil ash.

(Occup Environ Med 1995;52:353-358)

Keywords: nasal lavage; fuel oil ash; vanadium

The upper respiratory tract, specifically the nasal cavity, is the first target of and the first line of defence against ambient pollutants and irritants. It is also the portion of the respiratory system most easily accessible to morphological and pathophysiological evaluation. ${ }^{1-3}$ Therefore, the nasal cavity represents an ideal site for the development of biomarkers of events related to airborne exposures. There are a variety of methods that have been used for studying the nasal cavity. ${ }^{3}$ The preferred method for investigations of large populations should be non-invasive, of low risk, and simple to perform. Nasal lavage fulfils these requirements; it is a safe, simple, and inexpensive method for measuring the effect of acute inhalation exposures on the upper airway.

The polymorphonuclear leucocyte (PMN) cell is the predominant inflammatory cell in acute inflammation and has thus been used as a marker to study the acute cellular response of the upper airway to ambient contaminants. Previous studies conducted on subjects exposed to ozone, grain sorghum dust, cotton dust, and vanadium oxides showed increases in nasal lavage inflammatory cell counts, specifically PMNs. ${ }^{4-9}$

The use of nasal lavage for the investigation of exposures encountered in the workplace has been less extensively studied than its use in experiments. Nasal lavage studies have generally been experiments in which exposuresfor example, to ozone ${ }^{4}$ or cotton dust ${ }^{7}$-were controlled by the investigator. The subjects in experimental studies are generally young, healthy, non-smoking volunteers who differ from the typical chronically exposed workers. We undertook this study to investigate the use of nasal lavage in detecting an inflammatory response in workers after occupational exposure to fuel oil ash. Fuel oil ash contains, among other substances, vanadium pentoxide, a known respiratory irritant. ${ }^{10}$ Exposure to ambient vanadium pentoxide dust produces irritation of the eyes, nose, and throat. ${ }^{11-15}$ Other components of fuel oil ash 
deposits include carbon, iron, silica, sulphur, aluminium, and calcium. ${ }^{16}$ We hypothesised that occupational exposure to fuel oil ash, which contains vanadium oxides and vanadium sulphates, would induce an inflammatory response in the upper airways that could be detected with nasal lavage.

\section{Materials and methods}

STUDY DESIGN

The study design was guided by the results of our previous work on the kinetics of nasal lavage cell counts in unexposed subjects. ${ }^{17} \mathrm{We}$ decided that the lavage after exposure should be performed 72 hours after the baseline lavage to avoid residual effects (washout) of the baseline lavage on the lavage after exposure. As the inflammatory response to fuel oil ash is probably an acute response, the nasal lavage after exposure was performed about 12 hours after exposure.

The study was approved by the Institutional Review Board of the Harvard School of Public Health. The study was explained to the subjects before written and informed consent was obtained. At least one week before the start of the study, all subjects participated in a nasal lavage training session. Fifty male boilermakers and utility workers at a local electrical company volunteered to participate in the study and had a baseline lavage. Forty five subjects completed the lavage after exposure; five did not report for the second nasal lavage. Of the 45 subjects who completed both lavages, eight were excluded from the analysis because they reported symptoms of cold or flu at the time of the nasal lavage or in the previous two weeks. The 37 subjects whose results were used in the analysis consisted of 19 boilermakers and 18 utility workers. Generally, the boilermakers' exposure was higher than the utility workers who served as low exposed controls.

The boilermakers were all involved in the overhaul of a large oil fired boiler and turbine with an output capacity of $175 \mathrm{MW}$. The overhaul included the removal of sections of the boiler firebox (water wall tubes), ash pit, and air heater (air heat exchange section), as well as repair of the condenser and muddrum, which recirculates the condensed steam to the boiler. The work involved cutting with oxy-acetylene torches and the carbon arc process (Arcair process). After the removal of the old and damaged sections, the boiler ash pit and sections of the air heater and boiler firebox were replaced and welded in place with shielded metal arc and gas metal arc welding. Welding was also performed in the mud-drum and condenser. The utility workers were full time employees of the power company and consisted of mechanics, welders, labourers, painters, precipitator operators, supervisors, and laboratory workers.

All nasal lavages were performed in the morning, before the beginning of work on that day. The baseline lavage was performed on the first day back to work after at least 36 hours away. The lavage after exposure was performed about 72 hours after the baseline lavage and about 12 hours after exposure ended.

\section{EXPOSURE ASSESSMENT}

Occupational exposures to respirable particulate matter with an aerodynamic diameter of $\leqslant 10 \mu \mathrm{m}\left(\mathrm{PM}_{10}\right)$ were assessed with a personal sampling device consisting of a pump and impactor. ${ }^{1819}$ The number of work days each subject wore the personal sampling system varied from three study days, the maximum number of days between the baseline and lavage after exposure, to none. Exposure measurements were available for $37 \%$ of the total number of study days.

The personal air samples, collected on a Teflon membrane filter, underwent two sequential acid extractions with a combination of concentrated hydrochloric, hydrofluoric, and nitric acids (modified from procedure by Yamashige et al). ${ }^{20}$ The vanadium concentration was determined with a Perkin-Elmer Model 4100 ZL graphite furnace atomic absorption spectrometer equipped with a THGA graphite furnace, a Model AS-70 automatic sampler, and a fume extraction unit. The ratio of the mass of vanadium extracted in the second to first extraction was calculated. This extraction ratio was used to calculate the theoretical mass of vanadium that would be expected if four more extractions were performed. A total vanadium mass was calculated as the sum of the two actual and the four theoretical extractions. The filter extraction efficiency was determined as a ratio of the actual vanadium mass extracted to the theoretical total mass of vanadium extractable, and was expressed as a percentage; values ranged from $86 \%$ to $100 \%$. Also, the bulk extraction efficiency of removing vanadium from fuel oil ash was estimated by determining the percentage of vanadium extracted from Standard Reference Material 1648 (Urban Particulate Matter) of the National Institute of Standards and Technology (NIST). For the exposure response analyses, the vanadium concentrations were adjusted by both the filter extraction efficiency of the sample batch in which each sample was extracted, as well as the average bulk extraction efficiency (86\%). These adjusted vanadium concentrations are referred to as $V_{\text {adj }}$.

Each subject completed a self administered detailed work diary for each day between the baseline and the lavage after exposure. The work diary listed the tasks performed (welding, cutting, and grinding), and the specific location (boiler, airheater, and condenser) at which they were performed. Twenty nine task and location categories were identified. The mean of the personal air samples (one to 10 hour time weighted average) for each task and location category was used as the exposure level assigned to each category. With the mean exposure for each task and location category, we estimated occupational exposures for each subject during each of the three days between the nasal lavages at baseline and after exposure. 
Data on medical and smoking history and respiratory symptoms were obtained by a modified self administered American Thoracic Society DLD-78 questionnaire. ${ }^{21}$ Current cigarette smokers were defined as subjects who smoked at least one cigarette a day for at least the past year, or more than 20 packs in their lifetime, and who were still smoking within the past month. Non-smokers included subjects who were lifelong nonsmokers and ex-smokers. Ex-smokers were defined as subjects who had stopped at least one month before the study. Current smoking was coded as a dichotomous variable, yes or no. The subjects also completed an occupational history addendum that contained questions specific to their current and past occupations.

\section{NASAL LAVAGE PROCEDURE}

The nasal lavage procedure used in the study was adapted from Koren et al. ${ }^{4}$ Each subject was seated with his or her head tilted backwards at a $45^{\circ}$ angle. With a needleless syringe, $5 \mathrm{ml}$ of warm $\left(37^{\circ} \mathrm{C}\right)$, sterile, phosphate buffered saline (PBS) solution without $\mathrm{Ca}^{+2}$ and $\mathrm{Mg}^{+2}$, was instilled into one nostril. The subject held his breath and performed a partial swallow that closed off the nasopharyngeal cavity, thus improving the ability to hold the fluid in the nasal cavity. The saline solution was retained for 10 seconds, and then passively allowed to drain for 30 seconds into a sterile specimen cup. This procedure was repeated in the other nostril.

The volume of lavage fluid recovered was recorded and used to volume adjust the cell counts, which were expressed as cells $/ \mathrm{ml}$ of recovered fluid. After obtaining each sample, $0.5 \mathrm{ml}$ of $\mathrm{N}$-acetylcysteine (Mucomyst-10, Bristol Lab), a mucus digestant, was added. The sample was then vortex mixed for $30 \mathrm{sec}-$ onds and allowed to stand at room temperature for 30 minutes, centrifuged at $1000 \mathrm{~g}$ for 10 minutes, and the supernatant separated. The cells were resuspended in $0.5 \mathrm{ml}$ of PBS solution. With a haemocytometer, cell counts were performed on $0.1 \mathrm{ml}$ of the resuspended sample.

From the remaining resuspended cells, $0.15 \mathrm{ml}$ was used to prepare slides for differential cell counts. The slides were prepared by cytospin (Cytospin 2, Shandon) and were stained with Wright-Giemsa before being counted. Under oil immersion, 200 cells were examined. The differential cell count was used to calculate PMNs, eosinophils, and epithelial cells $/ \mathrm{ml}$ of recovered lavage fluid. The percentages of PMNs, eosinophils, and epithelial cells were calculated as a fraction of total cells.

STATISTICAL ANALYSIS

As the PMN counts before exposure varied widely both between and within subjects on different days, an adjustment for the PMN count before exposure will facilitate comparisons between those with different PMN counts before exposure. Furthermore, to avoid biases that may arise from measurement error, adjustment for the count before exposure (baseline), as well as that after exposure (follow up) is necessary. The potential bias that may occur results from regression to the mean whereby a spuriously high lavage count before exposure would be followed by a low follow up lavage count. ${ }^{22}$

The changes in both cell counts (PMNs and epithelial cells) and differentials (\% PMNs and \% epithelial cells) were calculated by subtracting the baseline lavage cell count or cell type percentage from the lavage cell count or cell type percentage after exposure, respectively. The adjusted changes in PMNs and epithelial cell counts $\left(\triangle \mathrm{PMN}_{\mathrm{adj}}\right.$ and $\Delta$ Epith $_{\text {adi }}$ ) were calculated by dividing the change in PMNs and epithelial cell counts by the average of the respective baseline and follow up lavage cell counts. The $\triangle P M N_{a d j}$ and $\Delta$ Epith $_{\text {adi }}$ were multiplied by 100 and are expressed as percentages. The adjusted changes in cell counts and change in cell type percentage were regressed on exposure and controlled for age and smoking.

The Wilcoxon rank sum test was used to compare the baseline and the follow up cell counts of cigarette smokers with those of nonsmokers. The Wilcoxon signed rank test was used to test if the changes in cell counts, adjusted for the average of the respective baseline and follow up nasal lavage, of both the smokers and non-smokers were different from zero. After stratification by smoking, each $\mathbf{P M}_{10}$ and respirable vanadium dust exposure index was regressed on the adjusted change in cell counts. The level of significance for all analyses was set at 0.05 .

\section{Results}

The analyses were performed on the 37 subjects who completed both lavages and did not report cold or flu symptoms at the time of the nasal lavage or in the previous two weeks. The 37 male workers ranged in age from 26 to 60 years, with a mean (SD) of 45 (9) years. Seven of the participants were smokers; all seven smokers reported smoking at least one cigarette in the morning before both the baseline and follow up lavage.

Personal sampling (one to 10 hour time weighted average) showed a range of $\mathrm{PM}_{10}$ concentrations of $50 \mu \mathrm{g} / \mathrm{m}^{3}$ to $4510 \mu \mathrm{g} / \mathrm{m} .^{3}$ Personal samples of respirable vanadium dust $\left(\mathrm{V}_{\mathrm{adj}}\right)$ had a range in concentration of 0.10 to $139 \cdot 2 \mu \mathrm{g} / \mathrm{m}^{3}$. Five exposure indices were calculated for both $\mathrm{PM}_{10}$ and $\mathrm{V}_{\text {adj }}$; these were the mean and peak exposures for each subject between lavages before and after exposure, as well as a subject's exposure on the day of the morning baseline lavage (day 1) and on the second and third day after the baseline lavage (day 2 and day 3, respectively). Tables 1 and 2 show the range, mean (SD), and median of the five exposure indices for $\mathbf{P M}_{10}$ and $\mathrm{V}_{\mathrm{adj}}$.

The mean (SD) of the volume of recovered fluid from both the before and after exposure lavages was $6.3(1.6) \mathrm{ml}$. Table 3 shows a summary of the data for the nasal lavage cell counts and differentials. The baseline 
lavage $P M N / m l$ counts ranged from 0 to 33700 with a mean (SD) of 2600 (5800) and a median of 400 . The lavage counts after exposure ranged from 0 to 24600 with a mean (SD) of 2800 (4800) and a median of 600. The adjusted change in $P M N s / m l$ $\left(\triangle \mathrm{PMN}_{\mathrm{adj}}\right)$ had a mean (SD) of $40 \%(100 \%)$, with a range of $-98 \%$ to $+200 \%$. The mean $\triangle \mathrm{PMN}_{\mathrm{adj}}$ was significantly greater than zero $(\mathrm{P}<0.05)$.

Table 1 Summary statistics for the five $P M_{10}$ exposure indices $\left(\mu g / m^{3}\right)$

\begin{tabular}{llll}
\hline $\begin{array}{l}\text { Exposure } \\
\text { index }\end{array}$ & Range & Mean $(S D)$ & Median \\
\hline Day 1 & 60 to 4510 & $1880(1660)$ & 1460 \\
Day 2 & 50 to 4510 & $1980(1730)$ & 1520 \\
Day 3 & 50 to 4510 & $2020(1830)$ & 1550 \\
Mean & 60 to 4510 & $1980(1660)$ & 1850 \\
Peak & 60 to 4510 & $2280(1880)$ & 2130
\end{tabular}

Day $1=$ exposure on the day of the morning baseline lavage; Day 2 = exposure on the second day after the baseline lavage; Day $3=$ exposure on the third day after the baseline lavage; Mean $=$ mean exposure during the 3 days between baseline and post-exposure lavage; Peak = peak exposure (one to 10 hour time weighted average) during the three days.

Table 2 Summary statistics for the five respirable vanadium dust exposure indices $\left(\mu g / m^{3}\right)$

\begin{tabular}{llrl}
\hline $\begin{array}{l}\text { Exposure } \\
\text { index }\end{array}$ & Range & Mean $(S D)$ & Median \\
\hline Day 1 & $0 \cdot 1$ to $32 \cdot 2$ & $9 \cdot 0(11 \cdot 0)$ & $3 \cdot 0$ \\
Day 2 & $0 \cdot 0$ to $32 \cdot 2$ & $8 \cdot 1(10 \cdot 3)$ & $2 \cdot 4$ \\
Day 3 & $0 \cdot 1$ to $32 \cdot 2$ & $9 \cdot 2(11 \cdot 0)$ & $3 \cdot 0$ \\
Mean & $0 \cdot 1$ to $31 \cdot 1$ & $8 \cdot 8(10 \cdot 2)$ & $3 \cdot 0$ \\
Peak & $0 \cdot 1$ to $32 \cdot 2$ & $10 \cdot 5(12 \cdot 4)$ & $3 \cdot 0$ \\
\hline
\end{tabular}

Explanations as for table 1 .

Table 3 Summary of data for nasal lavage cell counts and differentials

\begin{tabular}{|c|c|c|c|}
\hline Nasal lavage index & Range & Mean $(S D)$ & Median \\
\hline $\begin{array}{l}\mathrm{PMNs} / \mathrm{ml} \text { before exposure } \\
\mathrm{PMNs} / \mathrm{ml} \text { after exposure } \\
\Delta \mathrm{PMN} \text { adj }(\%) \\
\% \mathrm{PMNs} \text { before exposure } \\
\% \mathrm{PMNs} \text { after exposure } \\
\Delta \% \mathrm{PMNs}(\%) \\
\text { Epithelial cells } / \mathrm{ml} \text { before exposure } \\
\text { Epithelial cells/ml after exposure } \\
\Delta \text { Epithelial }{ }_{\text {adj }}(\%) \\
\% \text { Epithelial cells before exposure } \\
\% \text { Epithelial cells after exposure } \\
\Delta \% \text { Epithelial }(\%)\end{array}$ & $\begin{array}{l}0 \text { to } 33700 \\
0 \text { to } 24600 \\
-98 \text { to } 200 \\
0 \text { to } 89 \\
0 \text { to } 91 \\
-78 \text { to } 87 \\
0 \text { to } 26700 \\
100 \text { to } 8500 \\
-83 \text { to } 200 \\
0 \text { to } 100 \\
2 \text { to } 100 \\
-89 \text { to } 65\end{array}$ & $\begin{array}{l}2600(5800) \\
2800(4800) \\
40 \cdot 8(100 \cdot 3)^{\star} \\
34(35) \\
37(36) \\
3 \cdot 4(26 \cdot 4) \\
2500(4600) \\
2400(2600) \\
26 \cdot 7(81 \cdot 4) \\
53(37) \\
53(37) \\
-0.53(29 \cdot 3)\end{array}$ & $\begin{array}{c}400 \\
600 \\
11 \cdot 0 \\
22 \\
20 \\
0 \\
1200 \\
1200 \\
1 \cdot 3 \\
60 \\
56 \\
0 \cdot 7\end{array}$ \\
\hline
\end{tabular}

${ }^{\star} P<0.05$, Wilcoxon signed rank test used to test if different from zero.

$\mathrm{PMNs}=$ polymorphonuclear leucocytes; $\Delta \mathrm{PMN}_{\mathrm{adi}}\left(\Delta \mathrm{Epithelial}_{\mathrm{adj}}\right)$ is the change in $\mathrm{PMNs} / \mathrm{ml}$ (epithelial cells $/ \mathrm{ml}$ ) divided by the average of the respective before and after exposure value.

Table 4 Nasal lavage cell counts and differentials among smokers and non-smokers

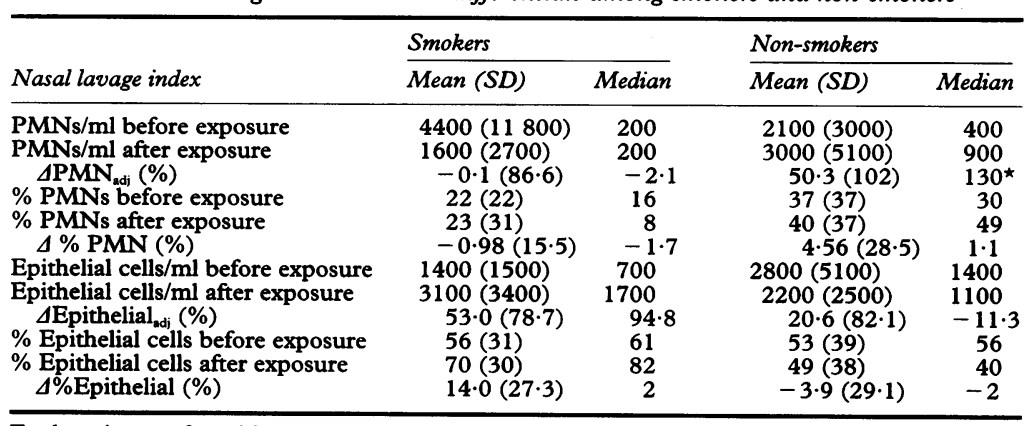

Explanations as for table 3 .
The baseline \% PMNs ranged from $0 \%$ to $89 \%$, with a mean (SD) of $34 \%(35 \%)$, and a median of $22 \%$. The $\%$ PMNs after exposure ranged from $0 \%$ to $91 \%$, with a mean (SD) of $37 \%(36 \%)$, and a median of $20 \%$. The change in $\%$ PMNs had a mean (SD) of $3.4 \%(26.4 \%)$, a median of $0 \%$ and ranged from $-78 \%$ to $87 \%$. The change in $\%$ PMNs was not significantly different from zero with either parametric or non-parametric tests. None of the $\mathrm{PM}_{10}$ or $\mathrm{V}_{\mathrm{adj}}$ exposure indices significantly predicted $\triangle \mathrm{PMN}_{\text {adj }}$ or the change in $\%$ PMNs.

The baseline lavage epithelial cell count ranged from 0 to 27700 cells $/ \mathrm{ml}$, with a mean (SD) of 2500 (4600), and a median of 1200 . The lavage counts after exposure ranged from 100 to 8500 epithelial cells $/ \mathrm{ml}$, with a mean (SD) of 2400 (2700), and a median of 1200. The adjusted change in epithelial cells $/ \mathrm{ml}$ ranged from $-83 \%$ to $200 \%$, with a mean (SD) of $26.7 \%(81.4 \%)$. The change in epithelial cells/ml was not significantly different from zero.

The baseline \% epithelial cells ranged from $0 \%$ to $100 \%$, with a mean (SD) of $53 \%$ $(37 \%)$, and a median of $60 \%$. The $\%$ epithelial cells after exposure ranged from $2 \%$ to $100 \%$, with a mean (SD) of $53 \%(37 \%)$, and a median of $56 \%$. The change in $\%$ epithelial cells had a mean (SD) of $-0.53 \%(29 \cdot 3 \%)$, a median of $0.7 \%$, and ranged from $-89 \%$ to $65 \%$. The change in $\%$ epithelial cells was not significantly different from zero. There were no significant relations between any of the five $\mathrm{PM}_{10}$ or $\mathrm{V}_{\mathrm{adj}}$ exposure indices and either the adjusted change in epithelial cell counts or the change in \% epithelial cells.

The mean baseline lavage PMN count in smokers was larger, although not significantly, than the mean baseline count in non-smokers: 4400 (11 800) v 2100 (3000), respectively (table 4). The mean (SD) of the lavage PMN count after exposure was $1600(2700)$ in smokers $v 3000$ (5100) in non-smokers, which was not significantly different. In nonsmokers, the mean $\triangle \mathrm{PMN}_{\text {adj }}$ was significantly greater than zero $(+50 \%, P<0.05)$, whereas in smokers the mean $\triangle \mathrm{PMN}_{\text {adj }}$ was not significantly different from zero $(-0 \cdot 1 \%, P>0.5)$. Nevertheless, even in non-smokers, there were no significant dose response relations between any of the $\mathbf{P M}_{10}$ or $\mathrm{V}_{\mathrm{adj}}$ exposure indices and $\triangle \mathrm{PMN}_{\text {adj }}$. The baseline and follow up \% PMNs, as well as the changes in \% PMNs, did not differ between smokers and non-smokers (table 4).

The mean (SD) of the baseline lavage epithelial cell count was 1400 (1500) in smokers $v 2800(5100)$ in non-smokers, which were not significantly different. The mean (SD) of the lavage epithelial cell count after exposure was 3100 (3400) in smokers $v 2200$ (2500) in non-smokers, which were not significantly different. The $\Delta$ Epiths $_{\text {adj }}$ were not significantly different between smokers and non-smokers. The \% epithelial cells before and after exposure, as well as the change in \% epithelial cells, did not differ between smokers and non-smokers (table 4). 


\section{Discussion}

Most investigations on volunteers exposed to ozone, ${ }^{45}$ grain sorghum dust, ${ }^{6}$ cotton dust ${ }^{78}$ or vanadium oxides, ${ }^{9}$ showed associations between inflammatory cell counts and exposure by nasal lavage. In our study, we found a significant increase in $\triangle \mathrm{PMN} \mathrm{N}_{\mathrm{adj}}$ after exposure in non-smokers but not in smokers. We did not detect, in either smokers or non-smokers, an increase in $\triangle \mathrm{Epith}_{\text {adi }}$, change in \% PMNs, or change in \% epithelial cells. These findings suggest that in non-smokers fuel oil ash exposure that ranged from a low of 50 to a high of $4500 \mu \mathrm{g} / \mathrm{m}^{3}$ was associated with an inflammatory response manifested as an increase in PMNs/ml. In non-smokers, there was considerable variability in $\triangle P M N_{\text {adj }}$. We were unable to show a dose-response relation between short term exposure to either fuel oil ash $\left(\mathrm{PM}_{10}\right)$ or respirable vanadium dust and $\Delta \mathrm{PMN}_{\text {adj }}$; none of the exposure indices significantly predicted $\triangle \mathrm{PMN}_{\mathrm{adj}}$. We also did not detect a dose-response relation between any of the exposure indices and the change in \% PMNs, the $\Delta$ Epith $_{\text {adj }}$, or the change in $\%$ epithelial cells.

The subjects studied were utility workers and boilermakers. They differed from the typical subjects in environmental chamber studies $^{47}$ in that they were more likely to be smokers, they tended to be older, and most importantly they have been chronically exposed to the contaminant under study (fuel oil ash containing vanadium oxides). They were also exposed to many workplace respiratory irritants, such as ozone from welding, and to complex mixtures of airborne pollutants, including particles, gases, and vapours. Precise measurement of all or even part of the exposure mixture was not possible. Therefore, $\mathrm{PM}_{10}$ and vanadium concentrations may not adequately reflect exposure to all inflammatory agents in the workplace.

In our study, we were unable to show a dose response relation between $\mathrm{PMN}$ cell counts and either $\mathbf{P M}_{10}$ or vanadium concentrations. One possible explanation for the lack of dose response relations is that chronic exposure to fuel oil ash may alter a subject's airway response to subsequent exposures. An adaptive response to repeated ozone exposure has been found..$^{23-25}$ Horvath et al showed that adaptation occurred within five days and consisted of a diminution or absence of a ventilatory response as well as a disappearance of the subjective discomfort usually seen with ozone exposure. $^{23}$ In our study the chronicity of exposure among the subjects may have led to adaptation that consisted of a blunted or absent inflammatory cell response. Unfortunately, as we lacked sufficient information, we were unable to control for a subject's exposure history, a history that may have confounded the dose response relation. In contrast with our study, in the experimental chamber studies a single exposure was delivered to subjects who had no known previous extensive exposure to pollutants. The importance of the difference in subject characteristics between our study of chronically exposed subjects and experimental studies in which subjects are naive to the exposure is unclear.

A second possible explanation rests with the assessment of exposure. The nasal cavity will deposit particles with larger aerodynamic diameters than the $\mathrm{PM}_{10} 0^{26}{ }^{27}$ If the $\mathrm{PM}_{10}$ exposure concentrations do not accurately reflect the dose to the nasal cavity, they will not be predictive of the inflammatory cell response as measured by nasal lavage. Also, exposure misclassification is a distinct possibility in our study due to the small number of personal samples per task and location category: 21 of the 29 categories of exposure estimates were based on three or fewer samples. The instability of the task and location category exposure estimates will impart random misclassification and bias our dose response results towards the null, thus decreasing the magnitude and significance of any association between dose and response.

A third possibility may be due to the presence of confounding exposures that were not accounted for in the analysis due to either an insufficient number of measurements or a lack of information. For instance, workers are exposed to ozone generated during welding: 23 of the 37 subjects were welders. Due to the lack of sufficient information on exposure to ozone, we were unable to control for confounding by ozone exposure. This confounding may bias our dose-response results toward the null. Respirator use, also not accounted for in the analysis, may also confound the relation between exposure and nasal lavage cell counts. People in high exposure areas may have used respirators more often, leading to a lowered delivered dose; this would again bias our dose-response results toward the null.

A fourth possible explanation for the inability to detect a dose-response relation is that the number of subjects studied (37) was too small to have had sufficient power to detect a dose-response relation. Finally, as the concentrations of respirable vanadium dust for the five exposure indices were uniformly low and ranged from $0 \cdot 1$ to $32.2 \mu \mathrm{g} / \mathrm{m}^{3}$, it is possible that these concentrations were insufficient to induce an inflammatory response. From our results, it is unclear if the lack of a doseresponse relation to vanadium is the result of low vanadium dust concentrations or a failure on the part of the nasal lavage technique to detect a response.

We did not find significant differences in baseline PMN or epithelial cell counts between smokers and non-smokers. Similarly, PMN and epithelial cell counts after exposure in smokers $v$ non-smokers did not differ significantly. When the change in PMNs adjusted for the average lavage values before and after exposure was stratified by smoking, there was a difference between smokers and non-smokers. For smokers, the adjusted $\triangle \mathrm{PMN}_{\mathrm{adj}}$ counts after exposure did not differ significantly from zero. These results may possibly reflect a diminished inflammatory response in smokers as a result of a toxic effect of chronic exposure to cigarette smoke. 
On the other hand, smoking may mask or overwhelm the effect of exposure to fuel oil ash on nasal lavage cell counts.

In non-smokers, $\triangle \mathrm{PMN}_{\mathrm{adj}}$ was significantly positive; it increased on average $50 \%$ $(P<0.05)$. This finding suggests that in nonsmokers exposure to fuel oil ash that ranged from a low of 50 to a high of $4500 \mu \mathrm{g} / \mathrm{m}^{3}$, is associated with an increase in PMN cell counts. We failed, however, to find a dose response relation between any of the exposure indices and the adjusted $\triangle \mathrm{PMN}_{\text {adj }}$ cell counts; none of the exposure indices significantly predicted the $\triangle P M N_{\text {adj }}$. As discussed previously, exposure misclassification and confounding may account for the failure to detect a doseresponse relation.

In summary, we found a significant increase in PMNs in non-smokers after exposure but not in smokers. This suggests that in non-smokers, exposure to fuel oil ash is associated with upper airway inflammation manifested as increased PMN cell counts. Non-smokers varied considerably in their $\triangle \mathrm{PMN}_{\mathrm{adj}}$. This may have precluded us from showing a dose-response relation between $\triangle \mathrm{PMN}_{\mathrm{adj}}$ and short term exposure to either $\mathrm{PM}_{10}$ or respirable vanadium dust. Factors that may mask the existence of a doseresponse relation include unmeasured confounding exposures, such as welding fumes and gases, as well as exposure misclassification. Given the complex composition of the workplace, $\mathrm{PM}_{10}$ and vanadium concentrations may not adequately reflect exposure to all workplace inflammatory agents.

In conclusion, the results of our study suggest that nasal lavage may be useful in occupational studies on inhalation exposures. As in previous studies, ${ }^{17} 28$ we found wide variability in PMN cell counts both within and between subjects, which were unrelated to either the concentration of $\mathrm{PM}_{10}$ or respirable vanadium dust exposure. This variability in cell counts may ultimately limit the use of nasal lavage. More investigations on the ability of nasal lavage to assess the response of the upper airways to inhaled pollutants are necessary to establish the use of this technique.

This work was supported by NIH grants ES05947, ES07069, and ES00002. We thank Marcia Chertok, Tom Dumyahn, Janna Frelich, Michael Nkwah, Lucille Pothier, Marlys Rogers, Nick Weidemann, and Dorie Wolf for research assistance. We are appreciative of the technical support given by Dr P Barry Ryan and Dr Karl Kelsey. We also thank Boston Edison Co, especially Forrest Carr, the director of safety, and Edison Co, especially Forrest Carr, the director of safety, and
John Embriano, the outage coordinator, the staff and boilerJohn Embriano, the outage coordinator, the staff and boiler-
makers of the International Brotherhood of Boilermakers, Iron makers of the International Brotherhood of Boilermakers, Iron
Ship Builders, Blacksmiths, Forgers, and Helpers of Local Ship Builders, Blacksmiths, Forgers, and Helpers of Local Lodge No 29, Quincy, MA, especially their president Paul
Meade; Utility Workers Union of America, AFL-CIO, Local
Lodge 369, Braintree, MA, especially William J Webb, Lodge 369, Braintree, MA, especially William J Webb,
Director of Safety and Health; and Thomas O'Connor Co, Director of Safety and Health; and Thomas O'Connor Co, especially James Murray. Results of this study were presented in part at the 1993 symposium on nasal toxicity and dosimetry of inhaled xeno
1 Anderson I. Effects of airborne substances on nasal function in human volunteers. In: Barrow CS, eds. Toxicology of the nasal passages. New York: Hemisphere, 1986; $143-53$.

2 Koenig JQ Pierson WE. Nasal responses to air pollutants. Clin Rev Allergy 1984;2:255-61.

3 Pipkorn U, Karlsson G. Methods for obtaining specimens from the nasal mucosa for morphological and biofrom the nasal mucosa for morphological

4 Koren HS, Hatch GE, Graham DE. Nasal lavage as a tool in assessing acute inflammation in response to inhaled pollutants. Toxicology 1990;60:15-25.

5 Frischer TM, Kuehr J, Pullwitt A, Meinert R, Forster J, Studnicka $M$, et al. Ambient ozone causes upper airways inflammation in children. Am Rev Respir Dis 1993;148: 961-4.

6 Von Essen S, O'Neill D, Robbins R. Grain sorghum dust inhalation at harvest causes nasal inflammation and peripheral blood neutrophilia. Am Rev Respir Dis 1993;

7 Harder S, Boehlecke B, Jacobs RR, Becker S, Devlin RB. Spirometric and inflammatory response of humans exposed to cotton dust containing different amounts of LPS. Am Rev Respir Dis 1993;147:A529.

8 Merchant JA, Halprin GM, Hudson AR, Kilburn $\mathrm{KH}$, McKenzie Jr WM, Bermanzohn P, et al. Evaluation before and after exposure: the pattern of physiological response to cotton dust. Ann NY Acad Sci 1974;221: 38-43.

9 Kiviluoto M, Rasanen O, Rinne A, Rissanen M. Effects of vanadium on the upper respiratory tract of workers in a vanadium factory. A macroscopic and microscopic study. Scand $\mathcal{F}$ Work Environ Health 1979;5:50-8.

10 Levy BS, Hoffman L, Gottsegen S. Boilermakers' bronchitis: respiratory tract irritation associated with vanadium pentoxide exposure during oil-to-coal conversion of a power plant. $\mathcal{F}$ Occup Med 1984;26:567-70.

11 Sjoberg S-G. Vanadium dust, chronic bronchitis and possible risk of emphysema: a follow-up investigation of possible risk of emphysema: a follow-up investigation of workers at

12 Williams N. Vanadium poisoning from cleaning oil-fired boilers. Br f Ind Med 1952;9:50-5.

13 Sjoberg S-G. Vanadium pentoxide dust: a clinical and experimental investigation on its effects after inhalation. Acta Med Scand 1950;138(suppl 238):1-188.

14 Lees REM. Changes in lung function after exposure to vanadium compounds in fuel oil ash. Br F Ind Med 1980; 37:253-6.

15 Zenz C, Berg BA. Human responses to controlled vanadium pentoxide exposure. Arch Environ Health 1967;14: 709-12.

16 Sjoberg S-G. Vanadium bronchitis from cleaning oil-fired burners. Archives of Industrial Health 1955;11:505-12.

17 Hauser R, Garcia-Closas M, Kelsey KT, Christiani DC. Variability of nasal lavage polymorphonuclear leukocyte counts in unexposed subjects: its potential utility for epidemiology. Arch Environ Health 1994;49:267-72.

18 Spengler JD, Ozkaynak H, Ludwig J, Allen G, Pellizzari ED, Weiner R. Personal exposures to particulate matter: Instruments and methodologies of P-TEAM. In: Proceedings of EPA/AWMA Symposium on Measurement of Toxic and Related Air Pollutants, Raleigh, NC. Pittsburgh, PA: APCA (VIP 13), 1989:449-63.

19 Thomas KW, Pellizzari ED, Clayton CA, Whitaker DA, Shores RC, Spengler J, et al. Particle total exposure assessment methodology (PTEAM) 1990 study: method performance and data quality for personal, indoor, and performance and data quality for personal, indoor, and outdoor monitoring. Fournal of the Experimental
of Environmental Epidemiology 1993;3:203-26.

20 Yamashige T, Yamamoto $M$, Sunahara $\mathrm{H}$. Comparison of decomposition methods for the analysis of atmospheric particulates by atomic absorption spectrometry. Analyst 1989;114:1071-7.

21 Ferris BG. Epidemiology standardization project. Am Rev Respir Dis 1978;118:1-88.

22 Davis CE. The effect of regression to the mean in epidemiologic and clinical studies. Am 7 Epidemiol 1976;104: 493-8.

23 Horvath SM, Gliner JA, Folinsbee LJ. Adaptation to ozone: duration of effect. Am Rev Respir Dis 1981;123: 496-9.

24 Folinsbee LJ, Bedi JF, Horvath SM. Respiratory responses in humans repeatedly exposed to low concentrations of in humans repeatedly exposed to low con
ozone. Am Rev Respir Dis 1980;121:431-9.

25 Farrel BP, Kerr HD, Kulle TJ, Saunder LR, Young JL. Adaptation in human subjects to the effect of inhaled ozone after repeated exposure. Am Rev Respir Dis 1979; 119:725-30.

26 Witek TJ. The nose as a target for adverse effects from the environment: applying advances in nasal physiologic measurements and mechanisms. Am $\mathcal{F}$ Ind Med 1993; 24:649-57.

27 Lippmann $M$. Deposition and clearance of inhaled particles in the human nose. Ann Otol Rhinol Laryngol 1970;79:519-28.

28 Graham D, Henderson F, House D. Neutrophil influx measured in nasal lavages of humans exposed to ozone. Arch Environ Health 1988;43:228-33. 